NOTAS

\title{
LA HERMENÉUTICA ANALÓGICA DE MAURICIO BEUCHOT: ENTRE UNIVERSALISMO Y PARTICULARISMO
}

Dora Elvira García*

\section{Planteamiento}

La ‘hermenéutica analógica’ propuesta por Mauricio Beuchot tiene una presencia importante en los diversos campos en los que se desarrolla y transita la filosofía actual. Desde la relación de la metafísica hermenéutica a la postulación de una hermenéutica política, la postura sostenida por Beuchot tiene una pertinencia clave para el intento de solución de problemas que han sido presentados como dilemas a lo largo y ancho de la reflexión filosófica.

El presente trabajo versará únicamente sobre una línea: la de la metafísica hermenéutica, por parecerme en principio la fundamental, la base sobre la que, si se comprende claramente, podrán sustentarse desarrollos ulteriores, por ejemplo cuestiones

\footnotetext{
* Universidad Intercontinental.
}

políticas y de interculturalidad, que se montan en estas consideraciones. Me parece fundamental dejar claridad sobre estos rubros, ya que dan juego y articulación a reflexiones sobre las que hoy la filosofía se preocupa hondamente, y sobre todo porque es posible lograr un equilibrio preciso y justificado sobre dilemas que han parecido irresolubles.

La consideración conjunta de la metafísica y la hermenéutica puede darnos una respuesta a la problemática de esta época de impotencia especulativa. Precisamente gracias a la metafísica, ${ }^{1}$ con un carácter hermenéutico se puede superar la escisión entre el mundo ideal y el real, evitando universalismos vacíos y contextualismos ciegos (que también

${ }^{1}$ Deliberadamente la llamo metafísica y no ontología, primeramente por seguir a Aristóteles, pero también porque ciertas críticas la agrupan con las metafísicas duras, con un sentido trascendente. 
NOTAS

son fundamentalismos absolutistas y nihilismos subjetivistas). Para quienes vislumbramos y pretendemos respuestas más vivas, digamos que esta metafísica hermenéutica se introduce en el mundo humano, contextualizado, circunstanciado, histórico, adquiriendo la viveza y riqueza que le evitan permanecer como algo alejado y trascendente.

La denominación 'metafísica hermenéutica' puede parecer extraña, sin embargo lo es sólo en el nombre, ya que el mismo Aristóteles señala en su Metafísica la posibilidades del ser que se dice de diferentes maneras $o$ en diferentes sentidos. ${ }^{2}$

Las estructuras metafísicas son descubiertas cognitivamente a través de la mediación humana, lo cual significa que no son estáticas e inamovibles. El hombre introduce y proporciona movilidad a aquellas concepciones y principios formales; sin esta participación humana particular y contextualizada, se queda en una caracterización universalista que quizá no responda a preocupaciones concretas. Esta mediación humana es de suma importancia, porque permite contextualizar las relaciones estructurales entre el ser y la realidad en la que el propio hombre se ubica.

${ }^{2}$ Cfr. Aristóteles, Metafísica, 1987, Madrid, Gredos, lb. Gamma, p. 151-2.
La mediación tensional que proporciona la hermenéutica presenta una contextualización que, por un lado, se alimenta de la diversidad de interpretaciones factibles, y por el otro, de la diversidad de lenguajes con el que se nombran esos principios de manera circunstanciada. La reflexividad y el pensamiento humano se presentan necesariamente por y a través del lenguaje, y por él es también posible que existan el diálogo y la comunicación.

Las cuestiones hermenéuticas en el conocimiento humano, considerado como función de una totalidad condicionada histórica y lingüísticamente, parecen superar a las metafísicas univocistas con sus pretensiones de encontrar estructuras ontológicas universales y fijas, así como de captar los entes individuales, subsumidos en la totalidad del ser. De ahí la importancia de, por un lado, presentar una interrelación tensional entre el mundo, la historia y el lenguaje, y por el otro, un referente, un criterio o razón, que en el plano de la metafísica es el ser; es decir, una correlación entre la hermenéutica y la metafísica. Es importante señalar esta vinculación ya que en la filosofía contemporánea hay quienes pretenden anular cualquier rasgo de carácter metafísico pensando que los aleja del mundo, del contexto y de lo circunstanciado. Su problema es preci- 
samente que no logran entender la metafísica en un sentido hermenéutico, de manera circunstanciada, orientándose hacia lo fragmentado, hacia el extremo relativista, en vez de complementar ambas posiciones. ${ }^{3}$

\section{Analogicidad: tensión y convergencia}

La preocupación de la metafísica desde los orígenes de la filosofía ha sido referida propiamente a lo que es el ser, a lo que está siendo, al conocimiento del ser de los entes, de todo lo real, así como de todo lo que participa de este ser, tratando de descubrir las estructuras que conforman la realidad.

Si la metafísica se interesa por el ser y realiza reflexiones, análisis y afirmaciones sobre él, podría pensarse que no requiere de un mundo histórico de experiencia, sin embargo es claro que no puede ser de tal modo, y que es aquí donde parece pertinente la consideración de la her-

${ }^{3}$ Hanna Pitkin ilustra esta problemática y hace un análisis de la justicia en la disputa de Sócrates y Trasímaco en el primer libro de la República de Platón y afirma que hay finalmente una tensión entre sustancia y forma, entre lo universal y deseable con lo real (cfr. Wittgenstein and Justice, 1972, University of California Press, p. 170-89 s.). menéutica, la cual merece incursionar como elemento necesario en la definición de la metafísica.

Si redefinimos la metafísica desde una perspectiva de la hermenéutica, parece ser que se amplía el ámbito de sus posibilidades y da cabida a un sinnúmero de opciones y revitaliza su aplicación en diferentes contextos de cultura. Así, la definición que se haría de la metafísica con una significación hermenéutica introduce una caracterización muy específica de la primera en cuanto contextualizada, individualizada y circunstanciada.

La fundamentación de la hermenéutica surge al mismo tiempo y de manera conjunta a la de la metafísica, y no por separado. Parece ser que querer dar primacía a la una o a la otra sería como querer preguntarse lo que en el lenguaje coloquial sería la cuestión ¿quién fue primero, el huevo o la gallina?, cuestión que obviamente no nos llevaría a una respuesta convincente ni clara, ya que ambas surgen y se desarrollan paralelamente. Ellas se dan conjuntamente, presuponiéndose mutuamente, la una no se da sin la otra, en aras de no cerrarse o empobrecerse. ¿Cómo explicar la metafísica pura, trascendental, desencarnada, sin la incursión del elemento humano interpretador? ¿Cómo explicar el que pueda haber una interrelación entre los hombres y entre las diferentes 
NOTAS

culturas? No parece haber otra salida coherente además de la que conjunte ambas cuestiones. Ciertamente la metafísica es histórica, como lo es el hombre mismo; aquí la cuestión es precisar en qué consiste esa historicidad y en qué sentido se le considera.

La hermenéutica promueve el entendimiento, la comprensión, el diálogo, la argumentación y el raciocinio, de ahí que como consecuencia sea intersubjetiva y también posibilite la interculturalidad. Al no cerrarse a una sola realidad o a un único modo de apreciarla, posibilita una apertura hacia lo múltiple, hacia lo disímil, con su consecuente enriquecimiento.

El giro ontológico se ubica en la comprensión de lo que es el ser, concibiéndolo no como algo trascendente, más allá del espacio y el tiempo, no más allá de la vida y la materia, no más allá de la apariencia fenoménica y cambiante, no más allá del lenguaje y la interpretación humana, sino en y por todos ellos.

En el libro Gamma de la Metafísi$c a$, después de recordarnos que el ser "se dice en varios sentidos", ${ }^{4}$ Aristóteles se tropieza con la irreductible pluralidad de las significaciones del ser. El ser del ente no tiene un solo sentido, su variedad propicia el que, ante la pluralidad de preguntas que

${ }^{4}$ Aristóteles, op. cit., lb. Gamma, 3, p. 151-2; lb. Z, 1, p. 320. realizamos, podemos responderlas específica y definidamente a cada una de ellas. Las preguntas por el ser son ineludibles y son las que finalmente definen al hombre como ser cuestionante ante su problematicidad. Cuando preguntamos lo que son las cosas, lo que es la realidad, este cuestionamiento nos remite directamente al lenguaje, ya que el ser se significa de diferentes y variados modos, y aunque se dispersa en esas significaciones, sin embargo, no se agota en ellas. El ser se dice de muchas maneras, pero siempre por relación a un término único, a un mismo referente, a una misma razón, a una cierta y mínima unidad, como dice Aristóteles, a algo común. ${ }^{5}$

La metafísica puede interpretar al ser bajo un modo determinado de comprensión histórico-lingüística. El mundo como lo entendemos y lo comprendemos es siempre un mundo real, que sólo es posible en el ser y por el ser. La interpretación metafísica sólo es posible en nuestro mundo histórico; una interpretación del ser en el pensar y el hablar humanos es posible y además necesaria, ya que el ser no se comprende definitivamente, de una vez por todas, porque no se puede abarcar absolutamente ni en el tiempo, ni en su comprehensión, como tampoco en su extensión,

${ }^{5}$ Ibid., p. 164. 
pues trasciende inalcanzablemente nuestro ser.

La metafísica (o, como diría Aristóteles, la ciencia del $\operatorname{ser}^{6}$ ) no tiene como objeto la totalidad de los seres, sino "lo que es común a todas las cosas”. La pregunta ¿qué es el ser? se remite a ¿qué significamos cuando hablamos del ser?, es decir, ¿cómo se entienden los hombres cuando hablan del ser? Aristóteles mismo afirma que la investigación acerca del ser se refiere a sus múltiples significaciones. Resulta vano querer separar el ser, como elemento ontológico, del discurso que mantenemos a propósito de él. (En este sentido, en el aspecto etimológico, la palabra 'ontología’ hace referencia a ese discurso, a esas palabras sobre el ser). Desde el momento en que el ser se dice, ese ser se dispersa en una pluralidad de significaciones. Por ello nos remitimos a la analogía, a la relación del ser y sus significaciones.

El ser es el punto común, la unidad de nuestras preguntas, de nuestras intenciones significantes. Esto no quiere decir que su significación sea única, sino que tiene diferentes y múltiples sentidos, lo cual se asocia con la teoría de la analogía, que representa esa intermediación entre el término unívoco y el equívoco, y en el cual se intenta salvaguardar las

${ }^{6}$ Ibid., p. 150. diferencias en el ámbito de cierta unidad. La analogía no se da en la realidad de manera unívoca, ella misma tiene grados y diferencias según los campos y órdenes en que se realiza. Podemos encontrar desde una analogía que se acerca a la univocidad hasta la que se acerca a la equivocidad. La analogía ordena aquella realidad que es múltiple, que es gradual y de ahí que ella misma sea analógica.

Considerando a la analogía como el procedimiento racional en el cual se respetan las diferencias dentro de la unidad, ${ }^{7}$ podemos ver que la analogía ordena, organiza, relaciona la multiplicidad y la diversidad. Puede ordenar, articular siempre y cuando haya algún elemento o elementos comunes. Si la diversidad es absoluta, la analogía no puede llevarse a cabo, así como tampoco puede si es un todo único, ya que no hay elementos a ordenar.

Por el hecho de que el ser, lo que existe, es analógico, es decir que se dice de muchas maneras, de ahí que tenga que ver, que se relacione con el carácter analógico de la interpretación. El ser es análogo, por consiguiente nuestra interpretación así lo será.

Esta cuestión de la analogía está íntimamente relacionada con la phrónesis (que es la analogía en el

${ }^{7}$ Ibid., p. 151. 
NOTAS

mundo de la acción), ambas concepciones de cuño aristotélico, en donde convergen relacionalmente lo universal y lo particular, en donde éste último se vuelve dominante, por la gran polisemia, pero que es sujetado a una significación suficientemente fija. En éste ámbito plural y variado de lo particular, es en donde la hermenéutica -a través de la analogía y la phrónesis- hace su aparición y su ejercicio, que resulta de gran enriquecimiento para el pensar filosófico.

Me parece que no es pertinente suponer la existencia de un dualismo ontológico, es decir, por un lado la naturaleza y por el otro la cultura, ya que, siguiendo a Aristóteles, se está considerando una ontología sin divisiones aunque sí con presentaciones, caracterizaciones y significaciones diferentes. Hay una unión dual, pero al fin una, que hace que los ámbitos disconformes converjan en ella.

Si se dicotomiza la realidad, se tienen consecuencias correlativas, como la separación entre teoría y práctica, entre la formalización o la justificación y la aplicación, y el mundo humano no es lo uno ni lo otro, sino que en él convergen una multiplicidad de realidades diversas que son conjuntadas analógicamente.

\section{Interdependencia}

La hermenéutica y la metafísica se requieren, existe una relación de condicionalidad mutua. Por un lado la hermenéutica presenta la manera histórica y cambiante del ser, su horizonte del mundo que no tiene una posición fija, sino que se va cambiando con nuevas experiencias, con otros seres humanos, con otras culturas. Con esto se amplía y se modifica ese horizonte y así podemos entender mejor lo nuevo, de tal modo que el horizonte del mundo de cada persona se amplía, se modifica, con nuevas experiencias, con otros seres humanos, con otros modos de vida, con otras culturas. Lo nuevo se introduce en el mundo de comprensión, de ahí la posibilidad de entenderlo mejor. Los horizontes se van ampliando en espiral gracias a este proceso hermenéutico, y la riqueza humana se expande también debido a las caracterizaciones nuevas.

La filosofía hermenéutica tiene que retomar aspectos metafísicos, y la metafísica requiere la hermenéutica.

Cuando se pretende reflexionar acerca de las condiciones metafísicas (u ontológicas) del ser, estas afirmaciones están determinadas históricamente, por ello se requiere de una interpretación hermenéutica. La hermenéutica requiere la refle- 
xión metafísica, pero ésta requiere la hermenéutica.

Lo que se dice del ser se dice a través del lenguaje, se da por mediación de la reflexión, de la lengua y de cuestiones culturales. Lo que podemos saber y expresar no se da sin alguna condición histórico-lingüística; el ser, sin embargo, rebasa cualquier expresión que pueda haber de él. Esto quiere decir que el ser es inefable y que esta característica conlleva a una movilidad, ya que ese ser inefable no es fijo y determinado, sino que se va recreando en diferentes momentos, de diferentes formas, en diferentes culturas. Las afirmaciones metafísicas son abiertas, lo dicho no es para siempre, reconociéndose así la característica potencialmente infinita del diálogo.

La hermenéutica permite el enfrentamiento y comportamiento en el mundo sin depender de reglas y métodos absolutos, y a la vez nos permite superar cualquier subjetivismo, al hacer reclamaciones que buscan un asentimiento general, al localizar ese punto común, ese referente, logrando evitar las polarizaciones, que tan dañinas consecuencias han tenido en la historia del pensamiento humano.

La idea a desarrollar en este escrito, y que es presentada en forma de dilema, probablemente debería presentarse en forma de pregunta: ¿universalismo univocista o particularismo equivocista? Son dos opciones filosóficas presumiblemente incompatibles y hasta opuestas, y digo 'presumiblemente', porque no intento sostener una extrapolación de ambas teorías, sino más bien reunirlas y conjuntarlas en un tercer elemento a través de los procesos mencionados: la analogía y la phrónesis.

La presencia de los dos rubros: universalismo-particularismo nos hace ver la realidad problemática e incierta entre lo normativo y lo descriptivo, entre lo real y lo ideal, entre el ser y el deber ser. El omitir o polarizar alguno de estos términos conlleva un empobrecimiento, de ahí la sugerencia de lo importante que es mantener dicha tensión dialéctica, incluyente y complementaria, para que finalmente haya un enriquecimiento mutuo. De ahí también la consideración de que la analogía responde no sólo en un ámbito epistemológico, sino que va a una realidad ontológica, por la cual las realidades no se agotan en definiciones de carácter unívoco, pero tampoco en derivaciones equívocas. Es una oscilación pendular entre un ámbito y otro, de ahí que más que una tracción fluctuante, sea una tensión, una relación y tirantez entre ambas realidades. Ni lo uno restrictivo, agotador de lo real, ni lo otro, que lleva al cauce de un relativismo. Gracias a 
NOTAS

la analogía podemos movernos de lo universal, de lo uno, a lo particular, a lo múltiple. En esta tensión interrelacional entre lo universal, entre lo objetivo y sus respectivas contrapartes, se cancelan y evitan las absolutizaciones de uno u otro campo, empobrecedoras y reduccionistas.

De ahí que este tercer momento sea de superación y de rebasamiento de los dos polos extremos, como consecuencia de su relación tensional.

Con estos supuestos de carácter común aceptados como criterios, aunados a las particularidades propias de cada cultura, se realiza la convergencia y la complementariedad, la mencionada tensión, que se traduce en analogía (en un sentido teórico) o en phrónesis (en un sentido práctico). Con la hermenéutica analógica, sostenida por Beuchot, se concuerdan las distintas particularidades, los diferentes puntos de vista, lo que hay en común y de universal, sin nulificar ninguno de los dos ámbitos, ni el universal ni el concreto, al evaluar y describir la realidad.

De esta manera, la hermenéutica analógica propicia la interculturalidad, al promover la comprensión y el entendimiento; pero, para esto, deberá aceptar al menos algunas cuestiones comunes, cuestiones que se tejen interrelacionalmente y posibilitan un algo común y compartido.

\section{III. ¿Phrónesis, virtud hermenéutica?}

Si aceptamos esta relación tensional, y la aplicamos o nombramos con el término de phrónesis, como relación analógica, esto no implica una relación necesaria con el relativismo, sino que es un correctivo útil contra el universalismo. Es relevante la noción de phrónesis, ya que procede de manera tal, que, por un lado, quita cualquier pretensión absolutizadora universalista y, por el otro, se relaciona con lo real, con lo contextual. De esta manera puede aplicarse y dar soluciones a los dilemas culturales interrelacionados, transesquemáticos y transparadigmáticos que se entretejen mutua y conjuntamente unos con otros como en una red. No se trata de hacer que la phrónesis sea emisaria del universalismo y sea únicamente un elemento aplicativo a principios de generalización, sino que ella misma tiene como punto de partida lo particular, para encontrar lo universal. De ahí la importancia de analizar qué clase de universalismo hay en el juicio phronético. La phrónesis funciona con esquemas o criterios conceptuales que son escogidos cuando no se puede invocar a criterios o referencias a priori establecidos de antemano, ya que se presentan tan incompati- 
bles como inaplicables con la realidad. Los criterios o referentes, como tales, probablemente no puedan definirse con toda claridad, sin embargo se entrecruzan, se entretejen entre los particulares como el punto en común.

Las capacidades de elección, la competencia señalada por los conceptos tales como buen juicio, phrónesis, sentido común, han sido discutidas por filósofos como Aristóteles y Kant (entre otros), cada uno de ellos con conceptos similares. Uno, el primero con la phrónesis como virtud, la cual es considerada por Aristóteles, en la Ética nicomaquea, ${ }^{8}$ como aquella actitud de la voluntad que se mantiene en un justo medio respecto de nosotros, definida racionalmente como lo haría el hombre sensato. El estagirita acoge tanto el ideal racional como la experiencia moral, poniendo acento en las condiciones concretas de la acción humana.

El segundo, Kant, con el juicio estético, y concretamente con el juicio reflexionante ${ }^{9}$ (que opone al determinante, en el cual lo que se da es lo universal), se refiere a aquellos juicios en los cuales falta lo universal y se propone como una idea con

${ }^{8}$ Cfr. Aristóteles, Ética nicomaquea, 1973, Madrid, Aguilar, lb. VI, cap. 5, p. 1242 s., y p. 1189-90.

${ }^{9}$ Cfr. Emmanuel Kant, Crítica del juicio, 1973, México, Porrúa, p. 194 s. propósitos de reflexión, y a través de ésta se encuentra dicho universal.

Aunque cada uno de estos filósofos lo refiere a un ámbito específico, uno al ético y el otro al estético, vemos que esta realidad a la que nos referimos, este mecanismo, la phrónesis, finalmente responde o debe responder y ubicarse desde el mismísimo ámbito metafísico, como elemento regulador, ante términos disímiles pero conteniendo un elemento común.

Al ubicar la dualidad de la realidad en este relacional phronético, se posibilita la erradicación de discusiones sectarias, encontrando el puente de unión conceptual entre principios, criterios y referentes, por un lado; y necesidades y realidades, por el otro.

En la Crítica del juicio, Kant señala al juicio phronético o juicio reflexivo o reflexionante, como la inclusión de lo particular en lo universal, en donde el universal es encontrado al mismo tiempo que le atribuimos el particular a él. La deliberación es sólo acerca de los particulares, de ahí que el juicio estético, concretamente el juicio reflexivo, sea señalado como símil con la phrónesis. De aquí que, me parece, tanto Aristóteles como Kant, en analogía con la hermenéutica analógica beuchotiana, nos dan luces para encontrar soluciones al problema universalis- 
NOTAS

mo-particularismo en el marco de nuestro mundo contemporáneo.

La claridad que nos brinda un marco referencial como el que se propone, proporciona gran riqueza y nos da luz a cuestiones que hacen referencia tanto a las problemáticas interculturales como a las políticas, en las cuales los contextos particulares van expresándose, haciendo que los principios, los criterios universales, se adapten a esas particularidades, de tal modo que se permeen en los diferentes contextos, pero siempre de abajo hacia arriba, corrigiendo lo universal en aras de lo particular, y siempre manteniendo clara la tensionalidad correlativa entre ambos ámbitos.

La phrónesis, como deliberación práctica que, ante la multiplicidad de experiencias humanas particulares, constituidas en gran parte por el habla, realiza una evaluación de los detalles, precisamente oscila entre dos polos. Por un lado, evalúa sin la dependencia de reglas, y por el otro presenta como exigencia la necesidad de liberarse de los confines de la subjetividad privada (se mantiene la tensión).

De nuevo aquí el principio analógico que necesariamente complementa lo universal con lo particular y viceversa, de tal forma que no puedan darse de manera excluyente ni separada. Si se separan las dos posiciones como dos ámbitos irrecon- ciliables, lo que se obtiene es una ruptura entre ellas por la negación de una o de otra. Así, el dilema propuesto al principio de este texto parece desvanecerse, ya que ambas dimensiones no se excluyen, es decir, el problema no tiene que plantearse en la disyunción, sino, como ya se dijo, en la conjunción, es decir, universalismo con contextualismo.

No tiene por qué haber contradicción en cuanto a la pretensión de fundamentación y el hecho de incluir lo contextual, el mundo real del sujeto, con sus circunstancias. Es difícil su complementariedad, pero no imposible. La búsqueda para compaginar validez, fundamentación con aplicación, parece que se resuelve en un universalismo llamémoslo concreto, contextualista, es decir, un universalismo de carácter prudencial. Es la armonización del universalismo con la pluralidad de las formas de vida, es una interrelación de algunos criterios fundamentales, referenciales, que van a lo contextual, evitando tanto la absolutización como la universalización de esos criterios o principios, pero sin abocarse hacia su contraria absolutización: contextualismo o relativismo.

Así pues, este problema se presenta de manera conjunta con otras cuestiones, relacionándose necesariamente con algunas preocupaciones surgidas a lo largo y en las 
reflexiones filosóficas que se expresan como binomios o díadas; sea, por ejemplo: objetivismo-relativismo, universalismo-contextualismo o formalismo-historicismo. Estas confrontaciones son vertientes de un mismo problema que se ha expresado a lo largo de la historia de la filosofía de diferentes e innumerables formas.

La riqueza de la phrónesis radica en considerarla como un juicio práctico aplicable. Parece importante 'des-etizar' la phrónesis, (es decir, no restringir a la phrónesis únicamente al campo ético, sino ampliar su lugar de acción a otros tales como el político, el cultural, etc.). Ver a dicha phrónesis como una competencia general que juega un papel crucial en todos los dilemas interculturales y transparadigmáticos, sin querer decir que con esto se le esté quitando su naturaleza ética, cognitiva, política o estética, sino que puede desarrollarse plenamente en todos esos variados ámbitos.

Es necesario evitar que esa phrónesis sea caracterizada por un universalismo vicario, con el costo de que se vuelva tan sólo un elemento más que se aplica a algunos principios de generalización, su campo de acción lo rebasa y tiene necesariamente y por definición propia que inmiscuirse en los problemas de la vida, en lo circunstancial, analizando los medios necesarios para alcanzar, si es el caso, algunos fines propuestos. De ahí que sea promisoria su presencia, como término intermedio, mediatizador y conjugante de los ámbitos que parecen ser tan incompatibles.

Es por este mecanismo mediatizador de la phrónesis como es posible la superación de la dicotomización radicalista y absolutizadora que tanto daño ha producido a lo largo de la historia de la humanidad, de su pensamiento y de la cultura, y por ende que resulta tan enriquecedora su presencia, dentro del ámbito de la hermenéutica, como su virtud propia.

Vemos entonces que la importancia de la hermenéutica analógica de Beuchot es considerada como ese mecanismo mediatizador, que se desarrolla análogamente a mecanismos similares tales como la phrónesis y el juicio reflexionante kantiano. A través de éstos podemos abrir vertientes muy interesantes en ámbitos y campos filosóficos no sólo restringidos al espacio de la metafísica, sino, como lo he hecho en otros trabajos, incursionando en lo político, como elemento equilibrante similar y análogo a procesos de ajuste político y social. 